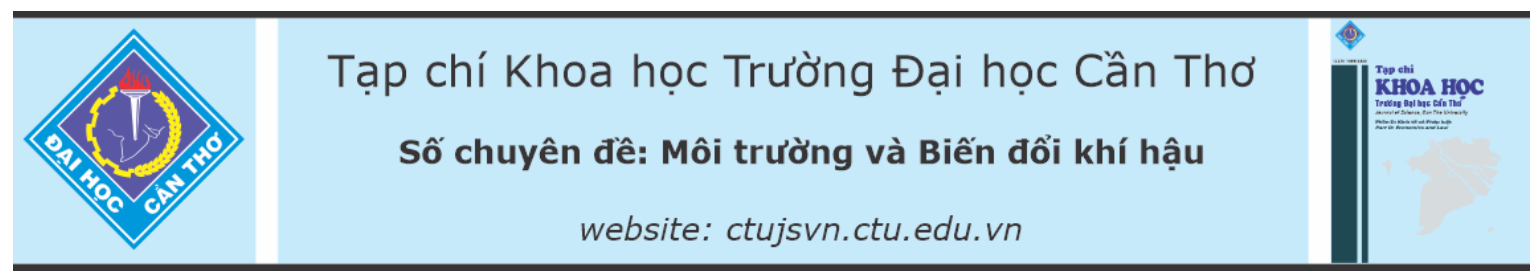

DOI:10.22144/ctu.jsi.2021.044

\title{
NGHIÊN CÚU NHU CẦU GẠO AN TOÀN CỦA NGƯỜI DÂN TẠI THÀNH PHỐ CẦN THƠ
}

\author{
Huỳnh Việt Khải ${ }^{1 *}$, Võ Thành Danh ${ }^{1}$ và Nguyễn Nhật Tâm ${ }^{2}$ \\ ${ }^{1}$ Khoa Kinh tế, Trường Đại học Cần Tho \\ ${ }^{2}$ Sinh viên Khoa Kinh tế, Truờng Đại học Cần Tho \\ *Nguoòi chịu trách nhiệm về bài viết: Huỳnh Việt Khải (email: hvkhai@ctu.edu.vn)
}

\section{Thông tin chung:}

Ngày nhận bài: 12/04/2021

Ngày nhận bài sủa: 27/05/2021

Ngày duyệt đăng: 15/11/2021

\section{Title:}

Study on the demand of Can

Tho city residents for safe rice products

\section{Tù khóa:}

An toàn thục phẩm, mức sã̃n lòng chi trả (WTP), phuoong pháp DBDC CVM, sản phẩm sạch hoạc hũu co

\section{Keywords:}

DBDC CVM, Food safety, safe or organic product, willingness to pay (WTP)

\begin{abstract}
The study analyzed the perception and identified the demand of Can Tho City residents for the proposed safe rice through the willingness to pay, estimated by the double-bounded dichotomous choice contingent valuation method (DBDC CVM). The results showed that most of the respondents were aware of the benefits of organic agriculture and the existence of food safety problems. The respondents were willing to pay for safe rice at the average price of 22,500 VND/kg, which was $75 \%$ higher than the normal rice price $(13,000 \mathrm{VND} / \mathrm{kg})$. This study also showed that if the respondents were having their own business, higher education, or income, the possibility of their willingness to pay for the proposed safe rice would become higher.
\end{abstract}

\section{TÓM TẮT}

Nghiên cứu được thực hiện nhằm phân tích nhận thức và xác định nhu cẩu của nguời dân thành phố Cần Tho đối với sản phẩm gạo an toàn thông qua mức sã̃n lòng chi trả được uớc luợng bằng phuoong pháp đánh giá ngẫu nhiên giới hạn kép (DBDC CVM). Kết quả cho thấy đa số đáp viên nhận thức được lợi ich của nông nghiệp hũu cơ và nhũng tồn tại các vấn đề về an toàn thưc phẩm hiện nay. Đáp viên săn lòng chi trả cho gạo an toàn khoảng 22.500 đồng $/ \mathrm{kg}$, cao hơn $75 \%$ so với múc giá thuờng được đưa ra ban đầu (13.000 đồng $/ \mathrm{kg}$ ). Nghiên cứu cũng cho thấy rằng nhũ̃ng đáp viên có nghề nghiệp là kinh doanh tư do, có trình độ học vấn hoạcc thu thập càng cao thì khả năng chi trả cho gạo an toàn nhiều hơn.

\section{GIỚI THIỆ}

Tại Việt Nam, các biện pháp làm tăng năng suất cây trồng hoặc giảm sâu hại và dịch bệnh trong nông nghiệp đa phần đều sử dụng phân hóa học, hóa chất bảo vệ thực vật, hoặc thuốc trừ sâu. Mặc dù khi sử dụng những hoá chất này mang lại hiệu quả đáng kể trong lĩnh vực nông nghiệp nhưng sẽ gây ô nhiễm môi trường, ảnh hưởng trầm trọng đến sức khỏe, và đời sống con người. Gần đây, khuyến khích sản xuất nông nghiệp sạch hoặc nông nghiệp hữu cơ (NNHC) là một trong những giải pháp hữu hiệu rất được quan tâm để giảm thiểu các tác động tiêu cực của nông nghiệp đến môi trường và con người. Nông nghiệp sạch hoặc hữu cơ là hệ thống nông nghiệp từ lâu đã trở nên quen thuộc với hầu hết các nước canh tác nông nghiệp trên thế giới với hình thức giảm hoặc loại bỏ phần lớn việc sử dụng phân bón tổng hợp, thuốc trừ sâu hóa học, các chất điều tiết tăng trưởng của cây trồng, hoặc các chất phụ gia trong thức ăn gia súc. 
Theo Tổ chức Nông Lương Liên Hiệp Quốc (FAO, 2017), nông nghiệp sạch hoặc hữu cơ có khả năng bảo đảm đủ nguồn lương thực nuôi sống dân số trên thế giới hiện nay nếu thực hiện song song với những biện pháp giảm thiểu tác động có hại cho môi trường. Mục đích của nông nghiệp sạch từ khâu canh tác đến quá trình tạo ra sản phẩm nông nghiệp hoàn thiện cung cấp cho người tiêu dùng đều phải duy trì sự an toàn cho hệ thống nông nghiệp và sức khỏe của con người. Ngoài ra, sản xuất nông nghiệp sạch thân thiện với môi trường tốn chi phí thấp nhưng mang lại giá trị kinh tế cao giúp cải thiện được đời sống cho nông dân ở các nước đang phát triển.

Tại Việt Nam, nông nghiệp sạch và hữu cơ đang được nhà sản xuất và người tiêu dùng quan tâm trong bối cảnh yêu cầu về an toàn thực phẩm và bảo vệ môi trường ngày càng tăng. Bên cạnh đó, Việt Nam được Liên đoàn Quốc tế các Phong trào NNHC (IFOAM) công nhận là nước có sản xuất NNHC. Theo số liệu thống kê của IFOAM vào năm 2015, Việt Nam có 76.666 ha NNHC, tương đương $0,7 \%$ diện tích đất nông nghiệp với 3.816 nông dân sản xuất hữu cơ. Các sản phẩm NNHC chủ yếu của Việt Nam là gạo, tôm, khóm, cà phê, cacao, sữa, trà, rau, quả, quế, hồi, tinh dầu (Nguyễn Xuân Hồng, 2019).

Ngày nay, việc xuất hiện nhiều loại gạo bẩn, gạo giả, dùng công nghệ tẩy trắng gạo ngày càng tinh vi thì nhu cầu lựa chọn gạo ngon, gạo sạch, gạo an toàn để đảm bảo sức khỏe bản thân và gia đình là một nhu cầu chính đáng. Đặc biệt, đây là loại lương thực không thể thiếu cho bữa ăn hàng ngày của gia đình Việt Nam. Tuy nhiên, sản xuất gạo an toàn vẫn còn nhiều hạn chế và thị phần tiêu thụ chưa phát triển nhiều. Ngoài ra, hiện nay tuy có một số nghiên cứu về gạo an toàn nhưng việc tìm hiểu sâu về đánh giá và ước lượng nhu cầu sử dụng gạo an toàn không nhiều. Vì vậy, bức tranh rõ nét về nhu cầu sử dụng gạo an toàn của người dân tại thành phố Cần Thơ sẽ được trình bày trong nghiên cứu này. Đây là thông tin hữu ích để làm cơ sở cho các nhà làm chính sách có những giải pháp và chính sách thích hợp cho việc phát triển thị trường gạo an toàn trong tương lai.

\section{PHƯƠNG PHÁP NGHIÊN CÚU}

\subsection{Phương pháp thu thập số liệu}

Bản câu hỏi được xây dựng để tìm hiểu nhận thức, thái độ về cung và cầu nông nghiệp sạch và hữu cơ, thân thiện với môi trường, và mức sẵn lòng chi trả của đáp viên đối với gạo an toàn. Bản câu hỏi gồm bốn phần cụ thể sau: (1) Thực trạng sử dụng gạo của đáp viên bao gồm các câu hỏi về khối lượng gạo, giá gạo sử dụng hằng tháng và địa điểm mua gạo của đáp viên; (2) Đánh giá nhận thức của đáp viên trong vấn đề về an toàn thực phẩm cũng như các kiến thức mà đáp viên có được về tình hình gạo trên thị trường hiện nay như thế nào; (3) Giả định có nhãn hiệu "Gạo an toàn"; (4) Thông tin cá nhân của đáp viên. Kịch bản của "Gạo an toàn” được giả định như sau:

"Với mức độ phát triển nông nghiệp công nghệ cao như hiện nay thì vấn đề an toàn thực phẩm được quan tâm hàng đầu trong việc lựa chọn thực phẩm sử dụng cho bữa ăn hàng ngày. Tình hình chung tại Việt Nam với nền văn minh lúa nước lâu đời, lúa gạo luôn là thức ăn cần thiết trong cuộc sống. Để đảm bảo được việc an toàn thực phẩm, nhãn hiệu "Gạo an toàn" được ra đời để góp phần giải quyết cho người tiêu dùng sự an tâm. Hình thức canh tác nông nghiệp tạo ra "Gạo an toàn" với quy trình hạn chế tối đa sử dụng phân hóa học và các hoá chất bảo vệ thực vật, thuốc trừ sâu,... gây tác động lớn đến môi trường sinh thái và sức khỏe người tiêu dùng. "Gạo an toàn" sẽ góp phần bảo vệ môi trường, đảm bảo an toàn thực phẩm cho con người khi sử dụng loại thức ăn chính này; đồng thời sẽ làm tăng sự đa dạng sinh học cho hệ sinh thái, mang lại hiệu quả kinh tế với đầu ra cao và tiết kiệm được chi phí đầu vào. Nghiên cứu này đề xuất gạo với thương hiệu "Gạo an toàn" với giả định được viện lúa ĐBSCL phối hợp với Ủy ban tỉnh và thành phố trực thuộc Trung ương cung cấp. Nhãn hiệu "Gạo an toàn" đáp ứng các tiêu chí:

- Nguồn gốc và xuất xứ rõ ràng.

- Hạn chế tối đa sử dụng phân hoá chất và thuốc bảo vệ thực vật trong quá trình canh tác.

- Không sử dụng những loại hoá chất như: hương tạo mùi, tẩy trắng.

- Sản xuất và bảo quản sản phẩm theo đúng những tiêu chuẩn kỹ thuật cao nhất.

- Góp phần bảo vệ môi trường sinh thái xung quanh khu vực canh tác.

Tiếp theo, sự xuất hiện "Gạo an toàn" trên thị trường được giả định và nghiên cứu sử dụng câu hỏi theo cấu trúc của phương pháp đánh giá ngẫu nhiên giới hạn kép (DBDC CVM_ double-bounded dichotomous choice contingent valuation method) để ước tính mức sẵn lòng chi trả của đáp viên. Để dễ cho việc so sách giữa giá gạo thường và "Gạo an toàn", nghiên cứu giả định đáp viên đang mua gạo thường với giá 13.000 đồng $/ \mathrm{kg}$ (Mức giá này được tham khảo từ phỏng vấn một số người tiêu dùng và 
một số nghiên cứu trước) và hỏi liệu họ sã̃n lòng trả cao hơn với số tiền được trình bày ở Bảng 1 để mua loại gạo được trồng theo cách thức "an toàn" hay không. Với năm mức giá khởi điểm được đưa ra $17.000,19.000,21.000,23.000,25.000$ đồng $/ \mathrm{kg}$, bản câu hỏi có năm phiên bản khác nhau tương ứng với năm mức giá khởi điểm này. Theo phương pháp DBDC CVM, khi được hỏi các mức giá được thể hiện ở Bảng 1 , nếu đáp viên đồng ý trả với mức giá $B i d_{1}$ thì tiếp tục được hỏi mức giá cao hơn $B i d_{2}$. Còn nếu đáp viên không đồng ý với mức giá $B i d_{1}$ thì họ được hỏi tiếp mức giá $B i d_{2}$ thấp hơn $B i d_{1}$.

Bảng 1. Các mức giá được đề xuất theo phương pháp DBDC CVM

\begin{tabular}{crr}
\hline \multirow{2}{*}{ Bid1 } & $\begin{array}{r}\text { Bid 2 } \\
\text { (Bid2 }>\text { Bid1 })\end{array}$ & $\begin{array}{r}\text { Bid2 } \\
\text { (Bid2 }<\text { Bid1 })\end{array}$ \\
\hline 17.000 & 19.000 & 15.000 \\
19.000 & 21.000 & 17.000 \\
21.000 & 23.000 & 19.000 \\
23.000 & 25.000 & 21.000 \\
25.000 & 27.000 & 23.000 \\
\hline
\end{tabular}

Bài viết sử dụng phương pháp chọn mẫu thuận tiện với tiêu chí: tìm kiếm các hộ sống và làm việc tại thành phố Cần Thơ và phỏng vấn trực tiếp bằng bản câu hỏi được soạn sẵn. Phỏng vấn viên đến từng hộ gia đình, nếu được sự chấp thuận của đáp viên, phỏng vấn viên bắt đầu phỏng vấn. Nếu không, phỏng vấn viên đến hộ gia đình tiếp theo. Nghiên cứu phỏng vấn được 125 người dân ở thành phố Cần Thơ với mỗi phiên bản câu hỏi là 25 bản. Trong quá trình phỏng vấn, nếu đáp viên có bất cứ vấn đề nào không rõ thì người phỏng vấn giải thích để có thể thu được câu trả lời chính xác nhất. Việc thu thập số liệu thông qua 2 bước là trước tiên phỏng vấn thử nhằm loại bỏ một số sai sót trong quá trình phỏng vấn để bản câu hỏi hoàn thiện và dễ hiểu hơn, sau đó mới tiến hành phỏng vấn chính thức.

\subsection{Phương pháp phân tích số liệu}

Dựa theo nghiên cứu của Hanemann và Kanninen (1999), số liệu với bản chất của các câu hỏi lựa chọn được mô hình hóa bằng cách sử dụng mô hình định giá ngẫu nhiên giới hạn kép (DBDC $\mathrm{CVM}$ ). Cách tiếp cận này có ưu điểm là câu hỏi nối tiếp (follow-up question) cung cấp thêm thông tin để xác định chính xác hơn mức WTP. Hơn nữa, Hanemann et al. (1991) chỉ ra cách tiếp cận này có thể cải thiện hiệu quả khi ước tính WTP.

Mô hình được thực hiện bằng cách sử dụng lệnh "doubleb" trong phần mềm Stata để ước lượng mức sẵn lòng trả WTP đối với gạo an toàn với giả định cơ bản là WTP có thể được mô hình hóa bằng hàm tuyến tính như sau (Lopez-Feldman, 2012; Cranfield \& Robb, 2018):

$$
\mathrm{WTP}_{\mathrm{i}}\left(\mathrm{z}_{\mathrm{i}}, \mathrm{ui}\right)=\mathrm{z}_{\mathrm{i}} \beta+\mathrm{u}_{\mathrm{i}} \quad \text { với } u_{i} \sim N\left(0, \sigma^{2}\right)
$$

Trong đó, $z_{i}$ đại diện cho vectơ của các biến giải thích, $\beta$ là vectơ của các tham số, $u_{i}$ là sai số ngẫu nhiên. Trong mô hình $\mathrm{DBDC} C \mathrm{CVM}$, những người được hỏi đã đưa ra hai câu trả lời cho các câu hỏi WTP đã định sẵn, trong đó giá đầu tiên được đánh dấu là $t^{l}$ và giá tiếp theo được đánh dấu là $t^{2}$. Sau đó, WTP của mỗi người được hỏi thuộc một trong bốn loại sau:

$$
\begin{aligned}
& \text { Có - Có: } t^{2}>t^{1} v a ̀ t^{2} \leq W T P<\infty \\
& \text { Có - Không: } t^{1} \leq W T P<t^{2} \\
& \text { Không - Có: } t^{2}<t^{1} v a ̀ t^{2} \leq W T P<t^{1} \\
& \text { Không - Không: } 0 \leq W T P<t^{2}
\end{aligned}
$$

Để sử dụng các phản hồi này trong mô hình để ước tính WTP, các câu trả lời từ đáp viên đã được mã hóa như các biến nhị phân $y_{i}^{1}$ (trả lời câu hỏi cho giá WTP đầu tiên) và $y_{i}^{2}$ (phản hồi lại cho câu hỏi giá WTP thứ 2) tương ứng, trong đó giá trị 1 được đưa ra cho các biến nếu cá nhân trả lời "có" và 0 nếu câu trả lời "không". Với giả định mức WTP và $u_{i}$ phân phối chuẩn, xác suất phản hồi của đáp viên được mô tả bởi các biểu thức sau:

$$
\begin{aligned}
& y_{i}^{1}=1 \text { và } y_{i}^{2}=1: \quad \operatorname{Pr}\left(y_{i}^{1}=1, y_{i}^{2}=1 \mid z_{i}\right)= \\
& \operatorname{Pr}(Y, Y)=\Phi\left(z_{i}^{\prime} \frac{\beta}{\sigma}-\frac{t^{2}}{\sigma}\right), \\
& y_{i}^{1}=1 \text { và } y_{i}^{2}=0: \quad \operatorname{Pr}\left(y_{i}^{1}=1, y_{i}^{2}=0 \mid z_{i}\right)= \\
& \operatorname{Pr}(Y, N)=\Phi\left(z_{i}^{\prime} \frac{\beta}{\sigma}-\frac{t^{1}}{\sigma}\right)-\Phi\left(z_{i}^{\prime} \frac{\beta}{\sigma}-\frac{t^{2}}{\sigma}\right), \\
& y_{i}^{1}=0 \text { và } y_{i}^{2}=1: \quad \operatorname{Pr}\left(y_{i}^{1}=0, y_{i}^{2}=1 \mid z_{i}\right)= \\
& \operatorname{Pr}(N, Y)=\Phi\left(z_{i}^{\prime} \frac{\beta}{\sigma}-\frac{t^{2}}{\sigma}\right)-\Phi\left(z_{i}^{\prime} \frac{\beta}{\sigma}-\frac{t^{1}}{\sigma}\right), \\
& y_{i}^{1}=0 \text { và } y_{i}^{2}=0: \quad \operatorname{Pr}\left(y_{i}^{1}=0, y_{i}^{2}=0 \mid z_{i}\right)= \\
& \operatorname{Pr}(N, N)=1-\Phi\left(z_{i}^{\prime} \frac{\beta}{\sigma}-\frac{t^{2}}{\sigma}\right) .
\end{aligned}
$$

Phương pháp ước lượng hợp lý tối đa (maximum likelihood estimation) được áp dụng để ước tính các tham số $\beta$ và $\sigma$. Hàm $\log -$ likelihood (LL) sau đây được phát triển để tối đa hóa:

$$
\begin{gathered}
\sum_{i=1}^{n}\left[d_{i}^{Y, Y} \ln \left(\Phi\left(z_{i}^{\prime} \frac{\beta}{\sigma}-\frac{t^{2}}{\sigma}\right)\right)+d_{i}^{Y, N} \ln \left(\Phi \left(z_{i}^{\prime} \frac{\beta}{\sigma}-\right.\right.\right. \\
\left.\left.\frac{t^{1}}{\sigma}\right)-\Phi\left(z_{i}^{\prime} \frac{\beta}{\sigma}-\frac{t^{2}}{\sigma}\right)\right)+d_{i}^{N, Y} \ln \left(\Phi\left(z_{i}^{\prime} \frac{\beta}{\sigma}-\frac{t^{2}}{\sigma}\right)-\right. \\
\left.\left.\Phi\left(z_{i}^{\prime} \frac{\beta}{\sigma}-\frac{t^{1}}{\sigma}\right)\right)+d_{i}^{N, Y} \ln \left(1-\Phi\left(z_{i}^{\prime} \frac{\beta}{\sigma}-\frac{t^{2}}{\sigma}\right)\right)\right]
\end{gathered}
$$

Trong đó, $i=1, \ldots, n$ với $d_{i}^{Y, N}, d_{i}^{Y, Y}, d_{i}^{N, Y}$, và $d_{i}^{N, N}$ là các biến có giá trị bằng 1 hoặc 0 tùy thuộc vào trường hợp có liên quan cho từng cá nhân. 


\section{KẾT QUẢ VÀ THẢO LUẬN}

Bảng 2 thể hiện khái quát một số thông tin về đặc điểm của đáp viên. Độ tuổi trung bình của đáp viên khoảng 37 tuổi, thấp nhất là 21 tuổi, và cao nhất là 71 tuổi. Điều này cho thấy tất cả các đáp viên đều có tuổi từ 18 trở lên là đối tượng trưởng thành có thể là chủ hộ hoặc người có thu nhập chính trong gia đình, là những người có quyền tự quyết nên thông tin điều tra đảm bảo đáng tin cậy, phù hợp với yêu cầu. Tỷ lệ đáp viên là nữ giới chiếm đa số hơn $60 \%$ trong bài viết này có thể được giải thích là hầu hết nữ giới luôn đảm nhận việc trực tiếp lựa chọn và chế biến thực phẩm cho gia đình mỗi ngày thì sẽ cân nhắc chọn những thực phẩm an toàn nhất chăm 10 cho sức khỏe cả nhà, mặc dù nam giới là trụ cột gia đình nhưng ít phải thực hiện những việc này.

\section{Bảng 2. Đặc điểm của đáp viên}

\begin{tabular}{lrrrr}
\hline Tiêu chí & Trung bình & Độ lệch chuẩn & Giá trị nhỏ nhất & Giá trị lớn nhất \\
\hline Tuổi đáp viên (Tuổi) & 37,12 & 13,63 & 21 & 71 \\
Trình độ học vấn (Năm) & 14,16 & 2,99 & 5 & 18 \\
Giới tính nam & 0,392 & 0,49 & 0 & 1 \\
Thu nhập (Triệu đồng) & 7,36 & 4,63 & 1,5 & 25,5 \\
\hline
\end{tabular}

Nguồn: Số liệu điều tra, 2020

Trình độ học vấn của đáp viên trung bình khoảng 14 năm và gần $65 \%$ đáp viên có trình độ từ bật cao đẳng trở lên, chứng tỏ đáp viên có đủ nhận thức và dễ dàng tiếp cận được các thông tin về kỹ thuật sản xuất nông nghiệp sạch và hữu cơ. Thu nhập trung bình hàng tháng của các đáp viên khoảng 7,36 triệu đồng, trong đó đa phần đáp viên có mức thu nhập trung bình khoảng 3.000.000 - 6.000.000 đồng/tháng, chiếm 33,6\%; kế đến là mức thu nhập trung bình khoảng $6.000 .000-9.000 .000$ đồng/tháng, chiếm 26,4\%.

\section{Bảng 3. Kiến thức về NNHC của đáp viên}

\begin{tabular}{lrr}
\hline Yếu tố & Số lượng (người) & Tỷ trọng (\%) \\
\hline Hiểu rất rõ & 30 & 24,0 \\
Hiểu rõ & 50 & 40,0 \\
Hiểu ít & 44 & 35,2 \\
Chưa biết gì & 1 & 0,8 \\
\hline Tổng & 125 & 100 \\
\hline
\end{tabular}

Nguồn: Số liệu điều tra, 2020

Bảng 3 cho thấy mức độ hiểu biết về NNHC của đáp viên, tương ứng với 4 mức độ được đưa ra trong bản câu hỏi là hiểu rất rõ, hiểu rõ, hiểu ít, và chưa biết gì. Kết quả cho thấy rằng đa số đáp viên đều hiểu biết về $\mathrm{NNHC}$ với 30 đáp viên hiểu rất rõ (24\%), 50 đáp viên hiểu rõ $(40 \%)$, và 44 đáp viên hiểu ít $(35,2 \%)$.

Để đo lường kiến thức của đáp viên cũng như cung cấp thêm thông tin về loại gạo an toàn. Bài viết đưa ra bốn nhận định kiến thức về gạo an toàn và các lợi ích của gạo an toàn mang lại cho người tiêu dùng. Mỗi câu hỏi có 3 sự lựa chọn là "Tôi không biết", "Tôi biết ít" và "Tôi biết nhiều", đáp viên lựa chọn một đáp án tùy theo sự hiểu biết của mình về nhận định đó để đưa ra đáp án phù hợp. Bảng 4 trình bày kiến thức của đáp viên đối với gạo an toàn.

Bảng 4 cho thấy kiến thức của đáp viên về gạo an toàn đa số không biết và chỉ biết ít. Do gạo an toàn dựa trên nền tảng của $\mathrm{NNHC}$ nên nếu đáp viên biết kiến thức về NNHC sẽ quen thuộc ngay nhận định đầu tiên "Gạo an toàn là loại gạo được canh tác, sản xuất mà không sử dụng phân bón hóa học, thuốc bảo vệ thực vật nào trong quá trình canh tác đến khâu chế biến, bảo quản nhằm đảm bảo an toàn thực phẩm cho người tiêu dùng trong bửa ăn hằng ngày", có 27 đáp viên biết rõ $(21,6 \%), 82$ đáp viên biết ít $(65,6 \%)$, và 16 đáp viên không biết gì $(12,8 \%)$.

Người dân sinh ra và lớn lên tại thành phố đa phần không biết nhiều về quá trình hay kỹ thuật canh tác các loại gạo vì họ tiếp xúc trực tiếp với thành phẩm mà ít chứng kiến khâu canh tác nên nhận định "Quy trình sản xuất gạo an toàn là khép kín: chọn giống, gieo, đất, tưới nước, bón phân. Tất cả giai đoạn trên được thực hiện dưới sự giám sát chặt chẽ của những chuyên gia", chỉ có 16 đáp viên biết rõ chiểm tỷ lệ thấp $12,8 \%$, số đáp viên biết ít 61 người chiếm tỷ lệ cao $48,8 \%$, còn lại 48 đáp viên không biết về quá trình canh tác chiếm $38,4 \%$. 
Bảng 4. Kiến thức của đáp viên về gạo an toàn

\begin{tabular}{|c|c|c|c|}
\hline PHÁT BIỀU & $\begin{array}{r}\text { Tôi không } \\
\text { biết }\end{array}$ & Tôi biết ít & $\begin{array}{c}\text { Tôi biết } \\
\text { nhiều }\end{array}$ \\
\hline $\begin{array}{l}\text { 1. Gạo an toàn là loại gạo được canh tác, sản xuất mà không sử } \\
\text { dụng phân bón hóa học, thuốc bảo vệ thực vật nào trong quá trình } \\
\text { canh tác đến khâu chế biến, bảo quản nhằm đảm bảo an toàn thực } \\
\text { phẩm cho người tiêu dùng trong bữa ăn hằng ngày. }\end{array}$ & $(12,8 \%)$ & $(65,6 \%)$ & $(21,6 \%)$ \\
\hline $\begin{array}{l}\text { 2. Quy trình sản xuất gạo an toàn là khép kín: chọn giống, gieo, } \\
\text { đất, tưới nước, bón phân. Tất cả giai đoạn trên được thực hiện dưới } \\
\text { sự giám sát chặt chẽ của những chuyên gia. }\end{array}$ & $\begin{array}{r}48 \\
(38,4 \%)\end{array}$ & $\begin{array}{r}61 \\
(48,8 \%) \\
\end{array}$ & $\begin{array}{r}16 \\
(12,8 \%) \\
\end{array}$ \\
\hline $\begin{array}{l}\text { 3. Gạo an toàn luôn giàu dinh dưỡng, an toàn cho sức khỏe người } \\
\text { sứ dụng sản phẩm. Do trong sản phâm không có chứa các chất gây } \\
\text { hại cho sức khỏe nên cơ thể có thể dễ dàng hấp thụ các chất có } \\
\text { trong gạo an toàn. }\end{array}$ & $(44,8 \%)$ & $(36 \%)$ & $(19,2 \%)$ \\
\hline $\begin{array}{l}\text { 4. Gạo an toàn còn có tác dụng tốt đối với những người mắc bệnh } \\
\text { tim mạch, tiểu đường. Gạo an toàn có nhiều chất xơ, độ đường } \\
\text { huyết trong gạo cũng thấp hơn so với gạo trắng bình thường. Vì } \\
\text { vậy, gạo an toàn rất tốt cho đường tiêu hóa cũng như việc giảm } \\
\text { cân. }\end{array}$ & $(54,4 \%)$ & $(36 \%)$ & $(9,6 \%)$ \\
\hline
\end{tabular}

Nguồn: Số liệu điều tra, 2020

Gạo an toàn là loại gạo có thuộc tính mới, lạ lẫm so với người tiêu dùng nên hầu như kiến thức về gạo an toàn cũng mới mé, do đó phát biểu "Gạo an toàn luôn giàu dinh dưỡng, an toàn cho sức khỏe người sử dụng sản phẩm. Do trong sản phẩm không có chứa các chất gây hại cho sức khỏe, vì thế cơ thể có thể dễ dàng hấp thụ các chất có trong gạo an toàn" có số đáp viên không biết về đặc điểm này của gạo an toàn khá cao 56 (chiếm 44,8\%), một số đáp viên biết ít về loại gạo này có 45 người (chiếm 36\%), 24 đáp viên biểt nhiều do có đặc tính tương tự với các loại gạo hữu cơ mà họ đã và đang sử dụng (chiếm $19,2 \%$ ). Tiếp theo là phát biểu "Gạo an toàn còn có tác dụng tốt đối với những người mắc bệnh tim mạch, tiểu đường. Gạo an toàn có nhiều chất xơ, độ đường huyết trong gạo cũng thấp hơn so với gạo trắng bình thường. Vì vậy, gạo an toàn rất tốt cho đường tiêu hóa cũng như việc giảm cân" cũng có 45 người biết ít (chiếm 36\%) nhưng số người không biết lại ở mức cao 68 người (chiếm 54,4\%).

Nhìn chung, kiến thức của người dân về gạo an toàn còn rất hạn chế, vì vậy cần phải cung cấp nhiều thông tin hơn về gạo an toàn, cũng như lợi ích và tầm quan trọng của gạo này để người dân hiểu biết sâu hơn, từ đó nhu cầu về gạo tăng và $\mathrm{NNHC}$ thân thiện với môi trường sẽ được phát triển tốt hơn.

Bảng 5. Các vấn đề tiêu cực về gạo trên thị trường hiện nay

\begin{tabular}{|c|c|c|c|}
\hline PHÁT BIẾU & Tôi không biết & Tôi biết ít & Tôi biết nhiều \\
\hline \multirow{2}{*}{$\begin{array}{l}\text { 1. Gần đây trên thị trường xuất hiện thông tin về gạo giả, gạo } \\
\text { bẩn, gạo không rõ nguồn gốc xuất xứ làm người tiêu dùng } \\
\text { vô cùng hoang mang. }\end{array}$} & 2 & 42 & 81 \\
\hline & $(1,6 \%)$ & $(33,6 \%)$ & $(64,8 \%)$ \\
\hline \multirow{2}{*}{$\begin{array}{l}\text { 2. Gạo sử dụng thuốc bảo vệ thực vật, các hóa chất gây ảnh } \\
\text { hưởng đến hệ sinh thái khu vực canh tác và sức khỏe của } \\
\text { người dân xung quanh cũng như người tiêu dùng. }\end{array}$} & 3 & 39 & 83 \\
\hline & $(2,4 \%)$ & $(31,2 \%)$ & $(66,4 \%)$ \\
\hline $\begin{array}{l}\text { 3. Trong khâu bảo quản trong quá trình bán thì gạo thường } \\
\text { bi sử dung chất tẩy trắng, chất bảo quản giúp cho hat gạo }\end{array}$ & 7 & 69 & 49 \\
\hline nhẵn và đẹp nhưng không đảm bảo vệ sinh thực phẩm. & $(5,6 \%)$ & $(55,2 \%)$ & $(39,2 \%)$ \\
\hline $\begin{array}{l}\text { 4. Có nhiều thực phẩm được chế biến từ gạo như: bún, hủ } \\
\text { tiếu, ông hút gạo nhưng nếu được làm từ gạo kém chất lượng }\end{array}$ & 11 & 62 & 52 \\
\hline $\begin{array}{l}\text { không đảm bảo an toàn thực phẩm sẽ gây nhiều ảnh hưởng } \\
\text { đến sức khỏe người tiêu dùng. }\end{array}$ & $(8,8 \%)$ & $(49,6 \%)$ & $(41,6 \%)$ \\
\hline
\end{tabular}

Nguồn: Số liệu điều tra, 2020 
Bảng 5 cho thấy các đáp viên đa phần đều hiểu biết các vấn đề tiêu cực liên quan đến gạo trên thị trường hiện nay. Nhận định đầu tiên "Gần đây trên thị trường xuất hiện thông tin về gạo giả, gạo bẩn, gạo không rõ nguồn gốc xuất xứ làm người tiêu dùng vô cùng hoang mang" có 81 đáp viên biết nhiều với tỷ lệ $64,8 \%$, đáp viên biết ít 42 người với tỷ lệ 33,6\%. Về nhận định "Gạo sử dụng thuốc bảo vệ thực vật, các hóa chất gây ảnh hưởng đến hệ sinh thái khu vực canh tác và sức khỏe của người dân xung quanh cũng như người tiêu dùng", 39 đáp viên biết ít với tỷ lệ $31,2 \%$ và tỷ lệ biết nhiều $66,4 \%$.

Nhận định tiếp theo "Trong khâu bảo quản trong quá trình bán thì gạo thường bị sử dụng chất tẩy trắng, chất bảo quản giúp cho hạt gạo nhẵn và đẹp nhưng không đảm bảo vệ sinh thực phẩm" ít được người tiêu dùng biết đến chiếm $55,2 \%$ và số đáp viên biết nhiều 49 người, chiếm tỷ lệ $39,2 \%$. Cuối cùng là nhận định "Có nhiều thực phẩm được chế biến từ gạo như: bún, hủ tiếu, ống hút gạo nhưng nếu được làm từ gạo kém chất lượng không đảm bảo an toàn thực phẩm sẽ gây nhiều ảnh hưởng đến sức khỏe người tiêu dùng", đa phần đáp viên biết ít có 62 đáp viên $(49,6 \%)$, biết nhiều 52 đáp viên $(41,6 \%)$. Nhìn chung, người tiêu dùng ở thành phố Cần Thơ có kiến thức và hiểu biết khá rộng về các hiện tượng tiêu cực liên quan đến gạo nên họ có thể rất quan tâm đến an toàn thực phẩm khi lựa chọn gạo trong bữa ăn hàng ngày.

Sau khi phỏng vấn tìm hiểu kiến thức của đáp viên về gạo an toàn và những vấn đề liên quan đến gạo, nghiên cứu đưa ra tình huống giả định nếu có sự xuất hiện của gạo với thương hiệu "Gạo an toàn" trên thị trường và hỏi liệu người mua có sẵn lòng chi số tiền mua cao hơn so với gạo thông thường hay không. Bảng 6 tóm tắt các kết quả tỷ lệ sẵn lòng chi trả của người tiêu dùng cho "Gạo an toàn" với $Y_{l}$ là sự sẵn lòng trả cho mức giá $B i d_{1}$ và $Y_{2}$ là sự sẵn lòng trả cho mức giá $B i d_{2}$. Có khoảng $26 \%$ số đáp viên hoàn toàn không sẵn lòng trả, $60 \%$ sẵn lòng trả với mức giá $B i d_{1}$ và khi tiếp tục hỏi đến mức giá $B i d_{2}$ gần $61 \%$ đáp viên sẵn lòng trả.

\section{Bảng 6. Tỷ lệ sẵn lòng trả của đáp viên cho "Gạo an toàn"}

\begin{tabular}{lrr}
\hline Yếu tố & $\begin{array}{r}\text { Số lượng } \\
\text { (người) }\end{array}$ & $\begin{array}{r}\text { Tỷ trọng } \\
\mathbf{( \% )}\end{array}$ \\
\hline Hoàn toàn không sẵn lòng & 32 & 25,6 \\
Hoàn toàn sãn lòng & 58 & 46,4 \\
Sã̃n lòng với mức giá $B i d_{1}$ & 75 & 60,0 \\
Sã̃n lòng với mức giá $B i d_{2}$ & 76 & 60,8 \\
\hline
\end{tabular}

Nguồn: Số liệu điều tra, 2020

Bảng 7 cho thấy tỷ lệ đáp viên cho sự sẵn lòng trả giảm khi mức giá tăng lên. Khi đã đồng ý mức giá đầu tiên $B i d_{1}$ đưa ra, có 58 đáp viên tiếp tục đồng ý mức giá $B i d_{2}$ cao hơn mức giá $B i d_{1}$ chiếm tỷ lệ $46,4 \%$. Nếu đáp viên chấp nhận mức giá $B i d_{l}$ thì có khoảng 13,6\% đáp viên không chấp nhận mức giá $B i d_{2}$. Số đáp viên không đồng ý mức giá $B i d_{l}$ cũng không đồng ý mức giá $B i d_{2}$ chiếm $25,6 \%$. Khoảng $14,4 \%$ đáp viên không đồng ý mức giá $B i d_{l}$ nhưng đồng ý mức giá $B i d_{2}$ thấp hơn so với $B i d_{1}$. Kết quả cho thấy tỷ lệ đáp viên cho sự sẵn lòng trả giảm khi mức giá tăng lên và mức giá ban đầu $B i d_{l}$ ảnh hưởng đến quyết định sẵn lòng trả của đáp viên.

Bảng 7. Sự sã̃n lòng trả của đáp viên cho các mức giá của gạo an toàn

\begin{tabular}{ccccc}
\hline BID1 & \multicolumn{2}{c}{ BID1<BID2 } & \multicolumn{2}{c}{ BID1>BID2 } \\
\cline { 2 - 5 } (dồng) & Có - Có & Có - Không & Không - Không & Không - Có \\
\hline 17.000 & 18 & 3 & 2 & 2 \\
19.000 & 14 & 4 & 3 & 4 \\
21.000 & 12 & 5 & 5 & 3 \\
23.000 & 8 & 3 & 9 & 5 \\
25.000 & 6 & 2 & 13 & 4 \\
\hline Tồng & $58(46,4 \%)$ & $17(13,6 \%)$ & $32(25,6 \%)$ & $18(14,4 \%)$ \\
\hline
\end{tabular}

Nguồn: Số liệu điều tra, 2020

Nếu đáp viên không sẵn lòng trả cho cả hai mức giá $B i d_{l}$ và $B i d_{2}$ thì họ được hỏi thêm lý do không sã̃n lòng trả cho "Gạo an toàn" và kết quả được trình bày ở Bảng 8 . Số lượng đáp viên chọn lý do "Tôi thấy giá sản phẩm cao" là 19 , chiếm $59,4 \%$, có lẽ vì giá gạo đang dùng của đáp viên thường khá thấp hơn giá đưa ra cho "Gạo an toàn". 


\section{Bảng 8. Lý do không sã̃n lòng trả cho gạo an toàn}

\begin{tabular}{lrr}
\hline Lý do & Số lượng (người) & Tỷ trọng (\%) \\
\hline Tôi cảm thấy giá sản phẩm cao & 19 & 59,4 \\
Tôi cảm thấy loại gạo này không cần thiết & 4 & 12,5 \\
Tôi lo lắng loại gạo này không mang lại hiệu quả như mong đợi & 11 & 34,4 \\
(ví dụ tốt cho sức khỏe, tốt cho môi trường) & 6 & 18,8 \\
Tôi không có nhu cầu sử dụng & 12 & 37,5 \\
Tôi chỉ tin dùng các loại gạo trước giờ từng dùng & & \\
\hline
\end{tabular}

Nguồn: Số liệu điều tra, 2020

Với lý do "Tôi chỉ tin dùng các loại gạo trước giờ từng dùng" có 12 đáp viên chọn, chiếm $37,5 \%$ vì họ có thói quen tiêu dùng thường xuyên nên ngại việc thay đổi lựa chọn khác. "Gạo an toàn" cũng là loại gạo mới nên có lẽ độ tin cậy của người tiêu dùng chưa cao. Với lý do "Tôi lo lắng loại gạo này sẽ không mang lại hiệu quả như mong đợi” có 11 đáp viên, chiếm $34,4 \%$. Do chưa tiếp cận được nhiều thông tin về loại gạo an toàn nên có $12,5 \%$ đáp viên chọn lý do "Tôi cảm thấy loại gạo này không cần thiết" và $18,8 \%$ đáp viên chọn "Tôi không có nhu cầu sử dụng".

Bảng 9 trình bày kết quả ước lượng của mô hình DBDC CVM để tính khả năng chi trả của đáp viên đối với "Gạo an toàn". Mô hình 1 chỉ được ước lượng với biến độc lập là mức giá $B i d_{1}$ và $B i d_{2}$, trong khi mô hình 2 được phân tích bao gồm các biến quan trọng khác được xem là có khả năng ảnh hưởng đến khả năng chi trả cho "Gạo an toàn" như độ tuổi (Tuoi), giới tính (Gioitinh), số thành viên trong gia đinh $(S T V)$, trình độ học vấn $(T D H V)$, đáp viên có nghề nghiệp là kinh doanh tự do $(K D T D)$, thu nhập trung bình hàng tháng của đáp viên (Thunhap), và số điểm kiến thức của đáp viên (Kienthuc) là tổng số điểm kiến thức của đáp viên về gạo án toàn và các vấn đề tiêu cực về gạo trên thị trường hiện nay được tính từ các phát biểu ở Bảng 4 và Bảng 5 . Đáp viên được 1 điểm nếu trả lời "Tôi biết nhiều", được 0,5 nếu trả lời "Tôi biết ít", và 0 điểm nếu trả lời "Tôi không biết".

\section{Bảng 9. Kết quả ước lượng của mô hình tính mức sã̃n lòng trả của đáp viên bằng phương pháp DBDC} CVM

\begin{tabular}{|c|c|c|c|c|}
\hline \multirow{2}{*}{ Biến } & \multicolumn{2}{|c|}{ Mô hình 1} & \multicolumn{2}{|c|}{ Mô hình 2} \\
\hline & \multicolumn{2}{|c|}{ Hệ số Sai Số chuẩn } & \multirow{2}{*}{$\frac{\text { Hệ số }}{-20,37}$} & \multirow{2}{*}{$\frac{\text { Sai số chuẩn }}{37,53}$} \\
\hline Tuoi (Số năm) & & & & \\
\hline Gioitinh $(1=$ Nam, 0 = Nữ $)$ & & & $-2.007,88^{* *}$ & 897,94 \\
\hline STV (Số người) & & & $-219,74$ & 338,67 \\
\hline$T D H V$ (Số năm) & & & $490,59 * * *$ & 186,54 \\
\hline KDTD $(1=\mathrm{KDTD}, 0=$ Khác $)$ & & & $2.116,19 * *$ & $1.052,57$ \\
\hline Thunhap (Triệu đồng) & & & $619,09 * * *$ & 136,04 \\
\hline Kienthuc (Số điểm) & & & 590,80 & 444,21 \\
\hline Beta constant & $22.554,59 * * *$ & 547,21 & $9.776,65^{* *}$ & $4.413,06$ \\
\hline Sigma constant & $5.063,61 * * *$ & 643,69 & $3.573,64 * * *$ & 437,35 \\
\hline Giá trị trung bình WTP & 22.55 & 54,59 & 22.574 & \\
\hline (95\% CI) (đồng) & $(21.482,09-$ & $23.627,10)$ & $(21.710,74-2$ & $7,28)$ \\
\hline
\end{tabular}

Ghi chú: 95\% CI: Khoảng tin cậy 95\%; ***, **, * tuong ứng vói các múc ý nghĩa 1\%, 5\%, 10\%

Nguồn: Số liệu điều tra, 2020

Kết quả cho thấy các hệ số của biến giới tính (Gioitinh) mang dấu âm với mức ý nghĩa $5 \%$, tức là khả năng chi trả của đáp viên nữ cho "Gạo an toàn" cao hơn đáp viên nam. Hệ số của biến về trình độ học vấn, kinh doanh tự do, và thu nhập mang dấu dương với mức ý nghĩa thống kê từ $5 \%$ trở lên, nghĩa là những đáp viên có nghề nghiệp là kinh doanh tự do, có trình độ học vấn hoặc thu thập càng cao thì khả năng chi trả của họ cho "Gạo an toàn" cũng nhiều hơn. Điều này có thể giải thích là những đáp viên có trình độ và thu nhập cao thì họ nhận thức nhiều hơn về lợi ích của "Gạo an toàn" đối với sức khỏe của họ và môi trường xung quanh nên họ cũng sẵn sàng chấp nhận và chi trả nhiều hơn cho "Gạo an toàn" được để xuất. Kết quả phân tích cho thấy đáp viên sẵn sàng chi trả khoảng 22.500 đồng cho 1 $\mathrm{kg}$ "Gạo an toàn", cao hơn khoảng 9.500 đồng, tương đương $75 \%$ so với mức giá được đưa ra ban 
đầu (13.000 đồng/kg). Điều này chứng tỏ gạo an toàn đề xuất trong nghiên cứu được chấp nhận đúng như kỳ vọng của bài viết.

\section{KẾT LUẬn VÀ KIẾN NGH!}

Nghiên cứu sử dụng phương pháp DBDC CVM để tìm hiểu nhận thức cũng như nhu cầu của người dân thành phố Cần Thơ đối với sản phẩm "Gạo an toàn". Kết quả cho thấy đa số đáp viên nhận thức được lợi ích của NNHC và tồn tại các vấn đề về an toàn thực phẩm hiện nay. Mức sằn lòng chi trả trung bình của đáp viên cho "Gạo an toàn" được ước lượng khoảng 22.500 đồng/ $\mathrm{kg}$, cao hơn $75 \%$ so với mức giá thường được đưa $\mathrm{ra}$ ban đầu $(13.000$ đồng $/ \mathrm{kg}$ ). Nghiên cứu cũng cho thấy rằng những đáp viên có nghề nghiệp là kinh doanh tự do, có trình độ học vấn hoặc thu thập càng cao thì khả năng có khả năng chi trả cho gạo an toàn nhiều hơn. Để phát triển sản phẩm gạo an toàn, bài viết đưa ra một số kiến nghị về mặt chính sách như sau:

- Các cơ quan chức năng cần nâng cao nhận thức của người dân về vai trò của NNHC nói chung và vài trò gạo an toàn nói riêng, thông qua các kênh thông tin đại chúng hoặc tổ chức các buổi hội thảo, tuyên truyền tại nhiều địa phương. Để bảo vệ sức khỏe của người tiêu dùng cần có những công ty sản xuất gạo an toàn theo đúng quy trình từ khâu canh tác đến sản xuất đảm bảo chất lượng đúng và đủ như đã nêu ra, không ngừng nâng cao cải tiến loại gạo an toàn để tạo được lòng tin lâu dài cho sản phẩm ngày càng phổ biến với người tiêu dùng. Sản phẩm phải được cung cấp đầy đủ thông tin cần thiết đến người tiêu dùng thông qua bao bì, nhãn hiệu một cách minh bạch đảm bảo được vệ sinh an toàn thực phẩm sao cho xứng đáng với giá sẵn lòng trả của người tiêu dùng. Mở rộng các chi nhánh phân phối thuận tiện cho người tiêu dùng dễ tiếp cận.

- Để "Gạo an toàn" được đề xuất có thể tiêu thụ tốt trên thị trường thì sản phẩm nên bán ở mức giá tối đa cao hơn mức giá gạo thường khoảng $75 \%$; đồng thời công ty sản xuất "Gạo an toàn" nên chú trọng vào nhóm khách hàng mục tiêu là những gia đình có trình độ học vấn và thu nhập cao, hoặc có ngành nghề kinh doanh tự do. Ngoài ra, các cơ quan chức năng cần tăng cường công tác kiểm tra, rà soát chất lượng, các sản phẩm an toàn nhằm bảo vệ quyền lợi của người tiêu dùng và củng cố niềm tin từ họ. Tuy nhiên, do số quan sát của bài viết còn khá nhỏ so với tổng số dân thành phố Cần Thơ nên cần có một nghiên cứu sâu và chi tiết với số quan sát nhiều hơn để thể hiện rõ nét nhu cầu của người tiêu dùng ở thành phố Cần Thơ đối với "Gạo an toàn" được đề xuất này.

\section{LỜI CẢM TẠ}

Đề tài này được tài trợ bởi Dự án Nâng cấp Trường Đại học Cần Thơ VN14-P6 bằng nguồn vốn vay ODA từ chính phủ Nhật Bản.

\section{TÀI LIỆU THAM KHẢO}

Cranfield, J. (2018). Will consumers pay for voluntary testing for BSE? Double-bound CVM evidence from Canada. Journal of Food Products Marketing, 24(6), 697-723.

FAO. (2017). Plant health and food security. http://www.fao.org/3/a-i7829e.pdf, truy cập ngày 12 tháng 03 năm 2020.

Hanemann, M., Loomis, J., \& Kanninen, B. (1991). Statistical efficiency of double-bounded dichotomous choice contingent valuation. American Journal of Agricultural Economics, 7: 1255-1263. doi:10.2307/1242453.

Hanemann, W., \& Kanninen, B. (1999). The statistical analysis of discrete-response. In I. Bateman, \& K. Willis (eds), Valuing the environment preferences: Theory and practice of the contingent valuation method in the US, EC and developing countries (pp. 302-441). Oxford, UK: Oxford University Press.

Lopez-Feldman, A. (2012). Introduction to contingent valuation using Stata (MPRA Paper No. 41018). Toluca, Mexico: Centro de Investigacion y Docencia Economicas (CIDE).

Nguyễn Xuân Hồng. (2019). Nông nghiệp hũu co: triển vọng, thách thức và giải pháp, truy cập ngày 30/3/2020 tại https://kinhtenongthon.vn/nong-nghiep-huuco-trien-vong-thach-thuc-va-giai-phappost25403.html. 